\title{
Announcement
}

\section{CODATA Conference 1986}

The Tenth International codata Conference is to be held in Ottawa, Canada, on 14-17 July 1986, under the theme "Computer handling and dissemination of data". The sponsor for this event is the National Research Council Canada, with the collaboration of the Royal Society of Canada and the Government of Ontario, Ministry of Industry and Trade.

\section{Technical program}

The conference will include invited lectures and contributed posters. Four plenary, multidisciplinary sessions will deal with issues related to Data Structure and Access, Data Handling and Dissemination, International Aspects of data Cooperation and Exchange, and Data Validation. Another twelve discipline-oriented symposia will cover the following topics:

- data for biotechnical industries

- mapping in geophysics

- evaluation of materials properties

- data for natural resource industries

- biosciences data

- scientific and technical data bases

- advances in materials data bases

- modelling in the geosciences

- physical and chemical data for advanced technologies

- environmental data - the CoDATA view

- expert systems in the physical sciences

- data for industrial process control

To facilitate discussion and interchange of ideas, all contributed papers will be presented as posters. Poster sessions may be followed by workshops in which appointed rapporteurs will lead discussions on groups of related papers. Topics for the poster sessions are:

- geosciences data

- data-base management and data handling 
- national and international data programs

- materials data bases

- thermodynamic and phase equilibrium data

- bioscience, nutrition and toxicology data

- environmental and agricultural data

- chemical reaction, structure and kinetics

- physics data

\section{Data base demonstrations}

Facilities will be made available for scientific and technical source data base developers to give demonstrations during the afternoon of each day of the conference. In the case of mainframe data bases, these facilities will include the complimentary use of a terminal and modem for dial-up access to commercial telecommunication networks; in the case of microcomputer data bases, facilities will include table space and electrical power. Demonstrators will be responsible for their own telecommunication costs. Those wishing to give such demonstrations or requiring more information should contact the Executive Secretary CODATA '86 (see below), giving the appropriate particulars.

\section{Exhibition}

Provision is being made for a commercial exhibition of equipment and services relevant to CODATA's broad range of interests. This is clearly an excellent opportunity for suppliers of communication and information products and services (data-base producers and disseminators, computer equipment, telecommunication networks and publishers, for example) to reach scientific data professionals from as many as thirty countries.

For further information on the Tenth International codata Conference, please contact:

Huguette Lacoste, Executive Secretary CoDATA '86

Conference Services National Research Council Canada

Ottawa, Canada K1A 0R6

tel. (613) 993-9009; telex 053-3145

The Committee on Data for Science and Technology (CODATA) was established in 1966 by the International Council of Scientific Unions. Working on an international, interdisciplinary basis, cODATA seeks to improve the quality, reliability, and accessibility of data of importance to science and technology. 